to which the answers would be largely philosophical. If it is effective when applied to some for short spells it could presumably be much more effective if applied to all for long periods or continuously. That would put decompression in a similar category to the possibility of enhancing cerebral acuity and diminishing risk of infection by living continuously in a sterile chamber of hyperbaric oxygen-scientifically possible but on a commonsense basis nonsensical. For most obstetricians and their patients nature's abhorrence of a vacuum seems likely to prevail.

\footnotetext{
1 Heyns, O. S., Fournal of Obstetrics and Gynaecology of the British Empire $1959,66,220$.

2 Bletcher, J. A., and Heyns, O. S., Lancet, 1967, 2, 621

2 Bletcher, J. A., and Heyns, O. S., Lancet, 1967, 2, 621.
3 Heyns, O. S., in Abdominal Decompression, p. 50. Johannesburg, Witwatersrand University Press, 1963.

Heyns, O. S., Developmental Medicine and Child Neurology, 1962, 4, 473.

5 Bletcher, J. A., South African Medical fournal, 1965, 39, 960.

- Coxon, A., and Haggith, J. W., Fournal of Obstetrics and Gynaecology and the British Commonwsalth, 1971, 78, 49.

${ }^{7}$ MacRae, D. J., Mohamedally, S. M., and Willmot, M. P., fournal of Obstetrics and Gynaecology of the British Commonwealth, 1971, 78, 636 .

8 Coxon, A., Fairweather, D. V. I., Smyth, C. N., Frankenberg, J., and Vessey, M., Fournal of Obstetrics and Gynaecology of the British Commonwealth, 1973, 89, 1081 .

- Varma. T. R., and Curzen, P., Fournal of Obstetrics and Gynaecology of the British Commonwealth, 1973, 80, 0186.

10 Humphrey, M., Hounslow, D., Morgan, S., and Wood, C., fournal of Obstetrics and Gynaecology of the British Commonwealth, 1973, 80, 1075.
}

\section{Methoxyflurane Nephrotoxicity}

Whenever a new anaesthetic agent is introduced there is always a period when it is hailed as the answer to every anaesthetist's prayer. Methoxyflurane is hardly an exception, though it started with the great disadvantage that its blood-togas solubility ratio is as high as 13.0 , which means that the necessary tension in the brain to produce anaesthesia builds up slowly and an equally long time is needed for the patient to recover consciousness. In this respect methoxyflurane resembles trichloroethylene; but since it also has a very high lipoid solubility relatively low concentrations can be used to maintain surgical anaesthesia. Furthermore, these low concentrations do not irritate the respiratory tract, so that methoxyflurane has proved to be a useful anaesthetic agent in clinical practice.

Soon after its clinical debut there was a report ${ }^{1}$ that methoxyflurane might produce renal damage. In 1971 Mazze and his colleagues, ${ }^{2}$ in a controlled study, provided evidence that when the drug was given alone it could cause polyuric renal insufficiency. No precise dose-effect relationship was established, so it was not possible to say whether methoxyflurane when used in low concentrations in combination with other anaesthetic agents was likely to produce renal damage or not. Now Cousins and Mazze have taken the matter a stage further and have conclusively shown ${ }^{3}$ that when the concentration exceeds a certain level (2.0 M.A.C. hours-minimum anaesthetic concentration for surgical anaesthesia multiplied by the duration of the anaesthesia) then some renal damage occurs. Animal studies have also shown that if methoxyflurane is used in the presence of other potentially nephrotoxic drugs such as gentamicin $^{4}$ or the tetracyclines ${ }^{5}$ the effect is additive.

Methoxyflurane produces two important metabolic products in vivo-inorganic fluoride and oxalic acid. Fluoride is known to inhibit several enzyme systems and chronic ingestion leads to renal damage. It has been suggested that the renal damage is produced principally by fluoride inhibition of the enzyme systems necessary for sodium pumping in the ascending loop of Henle or early distal tubule. ${ }^{6}$ Oxalic acid has been ruled out as the causative agent since the type of renal damage and also the clinical signs in these cases were different from those of oxalic acid intoxication.

The result of many careful studies has been to establish without any doubt that if patients breathe a high concentration of methoxyflurane for an hour or more there is an increasing risk of renal damage, even in the presence of normal function. Fortunately, methoxyflurane has never found wide acceptance as an anaesthetic agent in the United Kingdom. It has, however, been shown to be useful when given in low concentrations for relief of pain in midwifery. ${ }^{7-9}$ Though no harm has yet been shown to result from the use of these low concentrations in the presence of normal renal function, it does seem clear that if the use of methoxyflurane is essertial a careful watch must be kept on both the concentration and the duration of administration.

\footnotetext{
1 Crandell, W. B., Pappas, S. G., and Macdonald, A., Anesthesiology, 1966, 27, 591 .

Mazze, R. I., Shue, G. L., and Jackson, S. H., Fournal of the American Medical Association, 1971, 216, 278.

${ }^{3}$ Cousins, M. J., and Mazze, R. I., Fournal of the American Medical Association, 1973, 225, 1611 .

4 Mazze, R. I., and Cousins, M. J., British fournal of Anaesthesia, 1973, 45, 394 .

5 Kuzucu, E. Y., fournal of the American Medical Association, 1970, 211 1162.

6 Wiseman, A., in Handbook of Experimental Pharmacology, ed. F. A. Smith, Vol. 20, part 2, p. 48. New York, Springer-Verlag, 1970

7 Latto, I. P., Rosen, M., and Molloy, M. J., British Fournal of Anaesthesia, $1972,44,391$.

${ }^{8}$ Yakaitis, R. W., Cooke, J. E., and Redding, J. S., Anesthesia and Analgesia, $1972,51,208$

9 Jones, P. L., Molloy, M. J., and Rosen, M., British fournal of Anaesthesia, $1971,43,190$.
}

\section{Gonorrhoea of the Pharynx}

In April 1970 Bro-Jørgensen and Jensen cultured gonococci from the pharynx of a man who was symptom-free a few days after an orogenital contact. This led them to culture pharyngeal material routinely for gonococci from all their patients in Copenhagen with suspected venereal disease. They have now ${ }^{1}$ completed tests on 804 men and 542 women infected with gonorrhoea and similar numbers free from that disease, a total of some 2,700 persons.

Culture of the pharynx showed Neisseria gonorrhoeae in 110 of these patients: 55 women, 43 heterosexual men, and 12 homosexual men. The pharynx was the only site affected in eight of the women, six of the heterosexual men, and two of the homosexual men. Among patients suffering from gonorrhoea, pharyngeal infection was found in $10 \%$ of the women, $7 \%$ of the heterosexual Danish men, $2 \%$ of the heterosexual foreign men, and no fewer than $25 \%$ of the homosexual men.

A consecutive series of 1,203 heterosexual Danish patients (523 women, 680 men) were asked about orogenital contact. The pattern of behaviour was similar in men and in women and in those with and without gonorrhoea. About $20 \%$ claimed never to have had orogenital contact, $75 \%$ had it frequently or fairly often, and about $35 \%$ at the most recent sexual contact. Orogenital contact was almost the rule for homosexual men; this was reflected in the high rate of pharyngeal infection in members of this group with gonorrhoea.

Pharyngeal gonorrhoea was usually clinically silent: $79 \%$ of patients were symptom-free. The others had sore throat with tonsillitis of varying degree, occasionally with exudates 